\title{
A special issue about hepatotoxicity and hepatocyte in vitro systems
}

\section{Ilkavets}

Published online: 18 July 2013

(C) Springer-Verlag Berlin Heidelberg 2013

In recent years, great advances in the development of hepatocyte in vitro systems have led to an improved understanding of the mechanisms of hepatotoxicity (Hewitt et al. 2007; Zellmer et al. 2010; Schug et al. 2013; Heise et al. 2012; Mielke et al. 2011). In this issue of the Archives of Toxicology, readers can enjoy one of the most comprehensive reviews ever published on the topic (Godoy et al. 2013). The more than 100-page compilation summarizes the current knowledge on liver function with particular emphasis on hepatotoxicity and addresses the development of adequate in vitro systems to study mechanisms of hepatotoxicity, metabolism, signaling, drug interactions, and clearance. The invited review, which is written by a consortium of outstanding experts in the field of liver physiology and toxicology, covers the following topics:

- Structure and cellular components of the liver, including non-parenchymal cells and zonal heterogeneity

- Regulatory genes and signaling pathways, including nuclear receptors

- Bile acid metabolism and transport

- Liver in vitro systems, including the isolated perfused liver, liver slices, isolated human hepatocytes, and cocultures with non-parenchymal cells

- 3D liver models

- Recent developments in cryopreservation

- Mechanisms of hepatocyte dedifferentiation and novel anti-dedifferentiation strategies

I. Ilkavets $(\bowtie)$

Molecular Hepatology, II Med, Medical Faculty Mannheim,

Ruprecht-Karls University of Heidelberg, Theodor-Kutzer-Ufer

1-3, 68170 Mannheim, Germany

e-mail: iryna.ilkavets@medma.uni-heidelberg.de
- Alternative models to primary human hepatocytes, including cell lines and stem cell-derived hepatocytes

- Hepatocyte in vitro systems to study apoptosis and DILI

- Hepatocytes in toxicogenomics

- Mathematical modeling and systems biology in hepatocyte research

The article is supplemented by an electronic appendix with standard operating procedures of the most frequently applied in vitro systems. The individual sections contain a list of key questions and take home messages, which the reader can select accordingly.

In addition to the comprehensive review by Godoy et al., seven other contributions are presented in this special issue of the Archives of Toxicology:

- Based on in vitro metabolizing systems, the mechanisms of the human hepatotoxic drug fenclozic acid were studied (Rodrigues et al. 2013)

- Three- and two-dimensional culture systems were compared with acetaminophen-induced hepatotoxicity (Schyschka et al. 2013)

- The study of CYP induction in isolated mouse hepatocytes by vanadium (Abdelhamid et al. 2013)

- The key role of CTNNB1 in acetaminophen toxicity in mouse liver hepatoma cells (Singh et al. 2013)

- The study of combined effects of carcinogens in mouse liver (Kuroda et al. 2013)

- The study of toxicokinetics of acrylamide in primary rat hepatocytes (Watzek et al. 2013)

- The study of glucose homeostasis in rat liver (Zhang et al. 2013)

We hope that this special issue will provide readers with a clearer understanding of the complex field of hepatotoxicity. 


\section{References}

Abdelhamid G, Amara IE, Anwar-Mohamed A, El-Kadi AO (2013) Modulation of cytochrome P450 1 (Cyp1) by vanadium in hepatic tissue and isolated hepatocyte of C57BL/6 mice. Arch Toxicol. doi:10.1007/s00204-013-1023-7

Godoy P, Hewitt NJ, Luebke-Wheeler J et al (2013) Recent advances in $2 \mathrm{D}$ and $3 \mathrm{D}$ in vitro systems using primary hepatocytes, alternative hepatocyte sources and non-parenchymal liver cells and their use in investigating mechanisms of hepatotoxicity, cell signaling and ADME. Arch Toxicol. doi:10.1007/s00204-013-1078-5

Heise T, Schug M, Storm D, Ellinger-Ziegelbauer H, Ahr HJ, Hellwig B, Rahnenfuhrer J, Ghallab A, Guenther G, Sisnaiske J, Reif R, Godoy P, Mielke H, Gundert-Remy U, Lampen A, Oberemm A, Hengstler JG (2012) In vitro-in vivo correlation of gene expression alterations induced by liver carcinogens. Curr Med Chem 19(11):1721-1730

Hewitt NJ, Lechón MJ, Houston JB, Hallifax D, Brown HS, Maurel P, Kenna JG, Gustavsson L, Lohmann C, Skonberg C, Guillouzo A, Tuschl G, Li AP, LeCluyse E, Groothuis GM, Hengstler JG (2007) Primary hepatocytes: current understanding of the regulation of metabolic enzymes and transporter proteins, and pharmaceutical practice for the use of hepatocytes in metabolism, enzyme induction, transporter, clearance, and hepatotoxicity studies. Drug Metab Rev 39(1):159-234

Kuroda K, Kijima A, Ishii Y, Takasu S, Jin M, Matsushita K, Kodama Y, Umemura T (2013) Flumequine enhances the in vivo mutagenicity of MeIQx in the mouse liver. Arch Toxicol. doi:10.1007/ s00204-013-1064-y

Mielke H, Anger LT, Schug M, Hengstler JG, Stahlmann R, GundertRemy U (2011) A physiologically based toxicokinetic modelling approach to predict relevant concentrations for in vitro testing. Arch Toxicol 85(6):555-563

Rodrigues AV, Rollison HE, Martin S, Sarda S, Schulz-Utermoehl T, Stahl S, Gustafsson F, Eakins J, Kenna JG, Wilson ID
(2013) In vitro exploration of potential mechanisms of toxicity of the human hepatotoxic drug fenclozic acid. Arch Toxicol. doi:10.1007/s00204-013-1056-y

Schug M, Stöber R, Heise T, Mielke H, Gundert-Remy U, Godoy P, Reif R, Blaszkewicz M, Ellinger-Ziegelbauer H, Ahr HJ, Selinski S, Günther G, Marchan R, Blaszkewicz M, Sachinidis A, Nüssler A, Oberemm A, Hengstler JG (2013) Pharmacokinetics explain in vivo/in vitro discrepancies of carcinogen-induced gene expression alterations in rat liver and cultivated hepatocytes. Arch Toxicol 87(2):337-345

Schyschka L, Sánchez JJ, Wang Z, Burkhardt B, Müller-Vieira U, Zeilinger K, Bachmann A, Nadalin S, Damm G, Nussler AK (2013) Hepatic 3D cultures but not 2D cultures preserve specific transporter activity for acetaminophen-induced hepatotoxicity. Arch Toxicol. doi:10.1007/s00204-013-1080-y

Singh Y, Braeuning A, Schmid A, Pichler BJ, Schwarz M (2013) Selective poisoning of Ctnnb1-mutated hepatoma cells in mouse liver tumors by a single application of acetaminophen. Arch Toxicol. doi:10.1007/s00204-013-1030-8

Watzek N, Scherbl D, Schug M, Hengstler JG, Baum M, Habermeyer M, Richling E, Eisenbrand G (2013) Toxicokinetics of acrylamide in primary rat hepatocytes: coupling to glutathione is faster than conversion to glycidamide. Arch Toxicol. doi:10.1007/ s00204-013-1054-0

Zellmer S, Schmidt-Heck W, Godoy P, Weng H, Meyer C, Lehmann T, Sparna T, Schormann W, Hammad S, Kreutz C, Timmer J, von Weizsäcker F, Thürmann PA, Merfort I, Guthke R, Dooley S, Hengstler JG, Gebhardt R (2010) Transcription factors ETF, E2F, and SP-1 are involved in cytokine-independent proliferation of murine hepatocytes. Hepatology 52(6):2127-2136

Zhang Z, Sun ZZ, Xiao X, Zhou S, Wang XC, Gu J, Qiu LL, Zhang XH, Xu Q, Zhen B, Wang X, Wang SL (2013) Mechanism of BDE209-induced impaired glucose homeostasis based on gene microarray analysis of adult rat liver. Arch Toxicol. doi:10.1007/ s00204-013-1059-8 